\title{
Psychosis as a confounder of symptom credibility testing in a transcultural sample
}

Citation for published version (APA):

Van der Heide, D., Boskovic, I., Van Harten, P., \& Merckelbach, H. (2020). Psychosis as a confounder of symptom credibility testing in a transcultural sample. Journal of Forensic Psychiatry \& Psychology, 31(1), 64-75. https://doi.org/10.1080/14789949.2019.1663899

Document status and date:

Published: 02/01/2020

DOI:

10.1080/14789949.2019.1663899

Document Version:

Publisher's PDF, also known as Version of record

Document license:

Taverne

Please check the document version of this publication:

- A submitted manuscript is the version of the article upon submission and before peer-review. There can be important differences between the submitted version and the official published version of record.

People interested in the research are advised to contact the author for the final version of the publication, or visit the DOI to the publisher's website.

- The final author version and the galley proof are versions of the publication after peer review.

- The final published version features the final layout of the paper including the volume, issue and page numbers.

Link to publication

\footnotetext{
General rights rights.

- You may freely distribute the URL identifying the publication in the public portal. please follow below link for the End User Agreement:

www.umlib.nl/taverne-license

Take down policy

If you believe that this document breaches copyright please contact us at:

repository@maastrichtuniversity.nl

providing details and we will investigate your claim.
}

Copyright and moral rights for the publications made accessible in the public portal are retained by the authors and/or other copyright owners and it is a condition of accessing publications that users recognise and abide by the legal requirements associated with these

- Users may download and print one copy of any publication from the public portal for the purpose of private study or research.

- You may not further distribute the material or use it for any profit-making activity or commercial gain

If the publication is distributed under the terms of Article $25 \mathrm{fa}$ of the Dutch Copyright Act, indicated by the "Taverne" license above, 


\section{Psychosis as a confounder of symptom credibility testing in a transcultural sample}

\section{Douwe Van Der Heide, Irena Boskovic, Peter Van Harten \& Harald Merckelbach}

To cite this article: Douwe Van Der Heide, Irena Boskovic, Peter Van Harten \& Harald Merckelbach (2020) Psychosis as a confounder of symptom credibility testing in a transcultural sample, The Journal of Forensic Psychiatry \& Psychology, 31:1, 64-75, DOI: 10.1080/14789949.2019.1663899

To link to this article: https://doi.org/10.1080/14789949.2019.1663899

\section{Published online: 05 Sep 2019.}

\section{Submit your article to this journal ๘}

\section{山ll Article views: 228}

Q View related articles $\square$

View Crossmark data $₫$

4

Citing articles: 2 View citing articles $₫$ 


\title{
Psychosis as a confounder of symptom credibility testing in a transcultural sample
}

\author{
Douwe Van Der Heide ${ }^{a, b *}$, Irena Boskovic ${ }^{c, d}$, Peter Van Harten ${ }^{e, b}$ \\ and Harald Merckelbach ${ }^{c}$
}

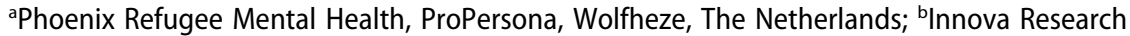
Institute, GGZ Centraal, Amersfoort, The Netherlands; 'Forensic Psychology Section, University of Maastricht, Maastricht, The Netherlands; ${ }^{\mathrm{d}}$ Forensic Psychology Section,

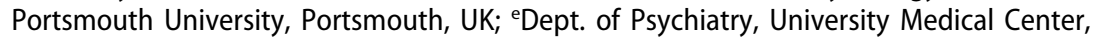
University of Maastricht, Maastricht, The Netherlands

\begin{abstract}
To check the credibility of impairments reported by refugees, so-called performance validity tests may be administered. We explored whether a psychotic condition may compromise performance on such test in patients admitted to a referral center for refugee mental health in the Netherlands $(n=231)$. We selected patients with no clear incentive to exaggerate their complaints $(n=80)$; psychotic patients in this subsample $(n=44)$ made significantly more errors on a simple forced-choice emotion recognition task than non-psychotic patients $(n=36)$, means being 9.0 $(\mathrm{SD}=6.8)$ and $5.9(\mathrm{SD}=5.1)$, respectively. Next, we selected patients with an incentive to deny complaints ( $n=24$ ); $79 \%$ of these patients had a psychotic disorder. Their failure rate on the emotion recognition test $(21 \%)$ was the same as the failure rate of a control group of Dutch chronic psychotic patients $(n=47)$, but significantly above that $(2 \%)$ of a control group of healthy controls $(n=51)$. We regard this as preliminary evidence that psychotic symptoms and/or antipsychotic medication may put a constraint on testing symptom credibility in refugees.
\end{abstract}

ARTICLE HISTORY Received 11 June 2019; Accepted 29 August 2019

KEYWORDS Symptom validity; transcultural psychiatry; symptom exaggeration; underperformance

\section{Background}

Refugees seeking asylum may be tempted to distort psychiatric symptoms and impairments. That is, they may exaggerate or even fabricate them; attribute symptoms to non-existent causes (e.g. by falsely claiming a traumatic history) or feign persistence of symptoms after successful treatment (Lipman, 1962). Faced with the dire consequences of expulsion, they may do so to comply with the criteria for medical asylum (Lustig, 2008). Using unstructured interviews, clinicians are poor in detecting distorted symptom presentations (Dandachi-FitzGerald,

CONTACT Douwe van der Heide d.vanderheide@ggzcentraal.nl

*Present affiliation of corresponding author

(c) 2019 Informa UK Limited, trading as Taylor \& Francis Group 
Merckelbach, \& Ponds, 2017). Hence, to screen for exaggerated, fabricated, falsely attributed or falsely maintained symptom presentations, dedicated tests known as Symptom Validity Tests (SVTs) have been recommended (Bush et al., 2005). Patients who engage in distorted illness presentations often fail on such tests (i.e. endorse rare or unlikely symptoms and/or perform below standards on a simple cognitive task), yet the reverse is not true: test failure does not necessarily indicate distorted illness presentation (Merckelbach, Dandachi-FitzGerald, van Helvoort, Jelicic, \& Otgaar, 2019; Young, 2014). Neither does a distorted symptom presentation rule out the presence of a genuine mental illness (Tracy, 2018).

There are a number of confounders (e.g. severe cognitive impairment; see e.g. Davis, 2018) that may suppress performance. In patients from ethnic minorities, cultural differences and language obstacles may cause failure on tests (see for a review: Nijdam-Jones \& Rosenfeld, 2017). Some SVTs have been translated into other languages and appear to function adequately in ethnic groups for which they were not originally designed (e.g. Montes \& Guyton, 2014). However, for culturally diverse migrants such as refugees, translated and validated instruments are not always available. One way to deal with this problem is to administer tests that do minimally depend on language (Erdodi, Nussbaum, Sagar, Abeare, \& Schwartz, 2017). Performance Validity Tests (PVTs), focusing on detection of exaggerated impairment, are a subtype of SVT with often a low verbal mediation. An example of such a PVT is Morel's Emotional Numbing Test (MENT; Morel, 1998), which was specifically designed to detect exaggeration of trauma-related symptoms, but has recently also become popular as a screener for a broad spectrum of symptom exaggeration (e.g. in soldiers who seek medical certification of occupational disability; Zimmermann et al., 2013). This test requires patients to discriminate between facial expressions of basic emotions (e.g. angry vs surprised). Prior to testing, patients are informed that persons with trauma-related problems often experience emotional numbing and that this may lead to mistakes in identifying other people's emotions. Typically, those who exaggerate their symptomatology produce considerably more errors on the MENT than genuine patients (see for a review, Ray, 2014). Some authors opine that tests such as the MENT hardly produce false positives because 'they can be successfully solved by virtually any adult, with the exception of patients suffering from severe neurocognitive disorders related to word processing, visual acuity, spatial neglect, or face processing' (Merten, Thies, Schneider, \& Stevens, 2009, p. 286).

Van der Heide and Merckelbach (2016), Van der Heide, Boskovic, and Merckelbach (2017) used a forced-choice PVT modeled after the MENT to screen patients of a psychiatric facility for refugees in the Netherlands. Patients with an incentive to exaggerate failed the forced-choice test significantly more often than patients with no such incentive. Yet, a considerable minority of patients (25\%) with an incentive to deny impairment also attained error scores beyond the cut-off. Why do patients who have no reason to exaggerate their illness fail on 
a forced-choice PVT? In the studies of Van der Heide and Merckelbach (2016), Van der Heide, Boskovic, and Merckelbach (2017), compulsory admission was regarded as an incentive to deny impairment, the reason being that symptom exaggeration would extend the compulsory admission. Could it be that psychotic patients were overrepresented in the negative incentive group, resulting in artificially inflated error scores on the forced-choice PVT? Evidence for this possibility can be found in the work of Dandachi-FitzGerald, Ponds, Peters, and Merckelbach (2011), who reported a similar rate of PVT failure (i.e. 25\%) in patients with psychotic symptomatology attending a non-forensic outpatient facility. On the other hand, Schroeder and Marshall (2011) administered several PVTs to patients with psychotic disorders $(n=104)$ and reported that they seldom failed on these tests, suggesting that PVTs are safe in this particular group. Likewise, Morel (1998) reported that schizophrenic patients made only few errors on the MENT, but his sample of schizophrenic patients was small $(n=17)$.

So, are psychotic symptoms an additional confounder when refugees are screened for distorted illness presentations, or not? To control for other major confounders, we selected patients without incentives to exaggerate from a referral center for refugee mental health and administered a PVT with low verbal mediation. For a preliminary answer to our question, we compared the error scores of psychotic and non-psychotic patients. Also, we checked whether a subgroup of patients with an incentive to deny impairments indeed contained a disproportionally large proportion of psychotic patients and compared their error scores and failure rates to those of a group of Dutch, chronic psychotic patients and a group of healthy controls.

\section{Methods}

\subsection{Participants}

Our study sample was selected from patients who had been admitted to a national referral center for non-forensic refugee mental health in the Netherlands. The average duration of admission in this referral center varied between 6 and 9 months. All patients hospitalized in the study period (2008-2012) were invited to participate; only a few patients $(<5 \%)$ refused or were mentally unfit to give consent. Thus, 231 patients ( 172 men; $74 \%$ ) were included, of whom 104 patients (45\%) originated from Africa, 58 (25\%) from the Middle East, 46 (20\%) from the former USSR, 14 (6\%) from the Far East, and nine (4\%) from former Yugoslavia. Mean age was 34 years $(S D=11.7$; range: 15-67 years). Of these patients, 63 (27\%) already obtained a residence permit; the others were still involved in a legal procedure for asylum.

A panel of social workers (see below) assigned 151 (65\%) inpatients to the group with positive incentives (incentives to exaggerate), 56 (25\%) inpatients to 
the group without incentives or with mixed incentives, and 24 (10\%) inpatients to the group with a negative incentive (an incentive to deny). All patients did the forced-choice emotion recognition test of this study, but only the error scores of the latter two groups were selected to test our hypothesis.

There are several centers for refugee mental health in the Netherlands. These facilities are specialized in the treatment of asylum seekers and refugees with resistant symptoms and/or admit patients because the referring clinicians lack the expertise to treat this group. Most centers offer primarily trauma therapy. The referral center described in the current study was selected for our study because, unlike the other centers, it was part of the inpatient facilities of a general psychiatric hospital and as such provided the option of compulsory admission. Accordingly, although $95 \%$ of the referred patients reported a history of traumatic events, they exhibited a much wider range of psychopathology than traumarelated symptoms, including psychotic symptomatology. Based on the diagnostic classifications mentioned in their discharge letters (Diagnostic and Statistical Manual of Mental Disorders, 4th ed., text rev.; American Psychiatric Association, 2000), 67 patients (29\%) had a psychotic disorder (schizophrenia spectrum and other psychotic disorder), 66 (29\%) an anxiety disorder of whom 60 (26\%) PTSD, $38(16 \%)$ an affective disorder, and eight (3\%) a dissociative disorder. In 76 patients (33\%), symptoms were classified as adjustment disorder. In 51 cases (22\%), there was a co-morbid personality disorder, in 32 cases (14\%) a co-morbid substance use disorder, and in six cases (3\%) data were missing.

As expected, there was an unequal distribution of psychotic symptomatology in the different incentive groups. Thus, 23 patients (15\%) in the positive incentive group, 25 (45\%) in the no/mixed incentive group, and 19 (79\%) in the negative incentive group had a psychotic disorder: Fisher-Freeman-Halton Exact $p<.001$. Similarly, in the subgroup with positive incentives, six patients (4\%) were admitted by court order. In the no/mixed incentive and in the negative incentive group, these numbers were 20 (36\%), and 19 (79\%), respectively: Fisher-Freeman-Halton Exact $p<.001$. Patients with psychotic symptoms were treated with either classic or atypical antipsychotics, except for those in the positive incentive group; their medication was as a rule tapered off.

The first control group consisted of native Dutch, chronic psychotic patients who were recruited from a long-stay psychiatric ward in another psychiatric hospital. In the Netherlands, this type of ward is reserved for patients with at least three continuous years of prior admission in other psychiatric wards. In total, 47 patients (33 men; 70\%) were included. Their mean age was 51 years ( $S D=11.7$; range: $25-69$ years). In total, 42 patients (89\%) had a primary DSM-IV-TR classification of schizophrenia; five patients (11\%) were diagnosed with a schizo-affective disorder. Their initial admission usually was by court order. All patients were treated with either classic or atypical antipsychotic medication. 
The second control group consisted of healthy controls. They were professional translators who served as interpreters in the clinic where the subsample of asylum seekers was recruited. They were not screened for mental or cognitive disorders, under the assumption that major cognitive impairment and psychotic disorder are not prevalent among professional interpreters. The controls were invited to take the forced-choice test (see below) themselves before assisting with the administration of the test. A total number of 51 interpreters (28 men; $55 \%)$ participated. Nineteen (37\%) interpreters originated from the Middle East, 17 (33\%) from Africa, five (10\%) from the former USSR, three (6\%) from the Far East, five (10\%) were Dutch or from Western Europe, and in two cases (4\%) information about the country of origin was missing.

\subsection{Instrument}

As a PVT with low verbal mediation, we used a research version of a forcedchoice effort task modeled after the Morel Emotional Numbing Test (MENT; Morel, 1998); it was introduced to the patients in the same way as the MENT (see above), by one psychiatrist who was a staff member of both referral center and the long-stay ward for Dutch chronic psychotic patients. Our version (Geraerts et al., 2009) consisted of 20 colored slides of 10 facial expressions posed by a man and a woman. Their expressions reflected happiness, frustration, sadness, anger, fear, calmness, surprise, shyness, confusion, and sleepiness. The slides were presented on a computer screen $(30 \times 38 \mathrm{~cm})$. Being a forced-choice test, each trial consisted of a correct and an incorrect answer option. In the first series of 20 trials, patients had to indicate which of two words (e.g. 'happy' versus 'surprised') that were presented best described the facial expression in the picture. In the second run of 20 trials, patients were presented with two different expressions simultaneously and only one emotion word. They had to identify the expression that best matched the word. In the final run of 20 trials, patients were shown two photographs and two words in each slide and these had to be connected in the right way. Slides of words and basic expressions were presented with no time limitations and participants could inspect them as long as needed to come up with an answer.

Emotional labels used in the test were translated and back-translated into several languages. However, as some patients reported to be unable to read or write and some translations were not available in the native language of the patient (e.g. a Russian translation for all patients from former Soviet Republics), a professional interpreter was present during the test to assist with the instructions and the key verbal labels when necessary.

Test performance was defined in terms of the total number of errors summed across the three runs. Morel (1998) recommended a cutting score of nine errors on the MENT, with scores above this level raising the suspicion that impairment is exaggerated. In a sample of Croatian war veterans elevated error 
levels (i.e. $>9$ errors) on a translated version of our forced-choice PVT were found to discriminate between treatment-seeking and compensation-seeking veterans (sensitivity: 92\%; specificity: 96\%; Geraerts et al., 2009).

\subsection{Procedure}

As a matter of routine, a professional interpreter was used to inform patients at the start of their admission to the referral center about the diagnostic procedures in the center: clinical interviews, observation, and psychological tests. They were also told that standard Western psychological tests might not yield useful results in patients with a different cultural background and that there would be an assessment in each individual case whether test results could be used or not. In addition, the patients were asked for consent for anonymous use of their data for scientific purposes. In case of unaccompanied minors, their legal representative was consulted. The study was approved by the Central Committee on Research Involving Human Subjects (CCMO).

Social workers of the hospital independently checked the medical files of the patients using a pre-defined list of incentives that may promote symptom exaggeration or denial of symptoms. One point was added for each condition potentially promoting exaggeration, such as: 1. An asylum procedure still in progress; 2. (Application for) a temporary refugee status issued for medical reasons; 3. Any other current procedure requiring a medical report indicating medical necessity, urgency or exemption (e.g. request for family reunion while the patient is not able to generate the necessary income demanded by Dutch law; a request for urgent change of housing or special housing arrangements; a request to be exempted from the criterion to pass a language test in the naturalization procedure). For each condition discouraging exaggeration the social workers subtracted a point. Such conditions would be: 1. A compulsory nature of the present admission; 2 . Any current procedure requiring a medical report indicating improved functioning or decreased need for medical treatment or scrutiny (e.g. a child custody procedure, a request for voluntary repatriation). Patients with one point or more were classified as having a positive incentive, patients with zero points were classified as having no/mixed incentives, and patients with minus one point or less were considered to have a negative incentive. Social workers evaluating incentive levels had no knowledge about the forced-choice PVT outcomes, and the psychiatrist who presented the forcedchoice PVT was not aware of the incentive status assigned by the social workers. However, as a staff member, the psychiatrist was involved in the treatment of the asylum seekers and had access to their medical files; so, in this respect blinding was incomplete.

In the subsample of Dutch psychotic patients, the forced-choice task was administered as part of a project to introduce a set of standard cognitive tests in order to evaluate rehabilitation interventions. The patients were informed that 
one of the tests was administered to assess whether cognitive tests could provide useful information for rehabilitation purposes.

Healthy controls, the interpreters, were asked to complete the task to serve as an additional check on the translations of the emotion words in the forced-choice task.

\subsection{Data analysis}

Because our data were not normally distributed (Shapiro-Wilk Ws $>.879$, ps $<.01$ ), we used descriptive and non-parametric statistics (Kruskal-Wallis and MannWhitney $U$ tests) to evaluate errors on the forced-choice PVT in the subsamples. We used Fisher exact $p$ to compare failure rates in subsamples, with failure defined as error rates $>9$ errors.

\section{Results}

The mean number of errors on our PVT in referral center patients (subsample 1) was $18.2,95 \% \mathrm{Cl}=17.0-20.7$, with a range of 0 to 54 errors; 142 patients (61\%) made more than nine errors. Looking at the different incentive groups, patients with a positive incentive made on average 24.8 errors ( $41 \%$ of the items), $95 \%$ $\mathrm{Cl}=22.5-27.1$, with a range of 0 to 54 errors; 121 (80\%) of these patients made more than nine errors. Patients with no incentives or mixed incentives made on average 8.2 errors ( $14 \%$ of the items), $95 \% \mathrm{Cl}=6.3-10.1$, with a range of 0 to 29 errors; 16 (29\%) of them made more than nine errors. Patients with a negative incentive made on average 6.3 errors ( $11 \%$ of the items), $95 \% \mathrm{Cl}=5.0-7.6$, with a range of 0 to 12 errors; five (21\%) made more than nine errors. A KruskalWallis test indicated that the error scores of the three incentive groups were significantly different, $X^{2}(2)=78.2, p<.01, \eta^{2}=.34$.

First, we compared psychotic patients of the referral center in the combined no/mixed and negative incentive groups $(n=44)$ with non-psychotic patients $(n=36)$ in these groups. Psychotic patients had higher error scores on the forced choice PVT than the non-psychotic patients, means being $9.0(S D=6.8$ ) and $5.9(S D=5.1)$. A Mann-Whitney $U$ test indicated that this difference was significant: $U=525.500, z=2.59, p<.05, \eta^{2}=.08$. Using the cutoff of nine errors, $14(32 \%)$ of the psychotic patients failed the test, whereas seven (19\%) of the non-psychotic patients did, a difference that did not attain significance, probably due to the small sample sizes involved (Fisher exact $p=.21$ ).

Next, we compared the patients with a negative incentive to the two control groups. In the control group of Dutch psychotic patients the mean number of errors was $5.7,95 \% \mathrm{Cl}=4.4-7,0$, with a range of 0 to 24 errors; ten $(21 \%)$ patients in this subsample made more than nine errors. To investigate whether the error scores of chronic psychotic patients differed from those of patients of 
the referral center with a negative incentive, we conducted a Mann-Whitney $U$ test: the error levels in both groups were similar, $U=483.0, z=.99, p=.32$.

In the healthy controls group, the mean number of errors was 3.4, 95\% $\mathrm{Cl}=2.7-4.1$, with a range of 0 to 12 errors; one person (2\%) made more than nine errors. The error scores of healthy controls were significantly lower than those of referral center patients with a negative incentive and the Dutch psychotic patients: $U=300.5, z=3.56, p<.01, r=.41$ and $U=821.0, z=2.70$, $p<.01, r=.27$ respectively (corrected alpha level $=.017){ }^{1}$

\section{Discussion}

Our findings suggest that psychotic symptoms may act as a confounder when refugees are screened for distorted illness presentations. First, in the combined no/mixed and negative incentive subsamples of the referral center, psychotic patients had higher error scores on the forced-choice PVT than non-psychotic patients. This finding is congruent with Hunt, Root, and Bascetta (2014), who found elevated error scores on PVTs in patients with schizophrenia and schizoaffective disorder (see also Glassmire, Toofanian Ross, Kinney, \& Nitch, 2016; Peters, Jelicic, Moritz, \& Jelinek, 2013), and also with studies that demonstrated a relative impairment of patients with schizophrenia in emotional recognition in facial expressions (for an overview, see Edwards, Jackson, \& Pattison, 2002).

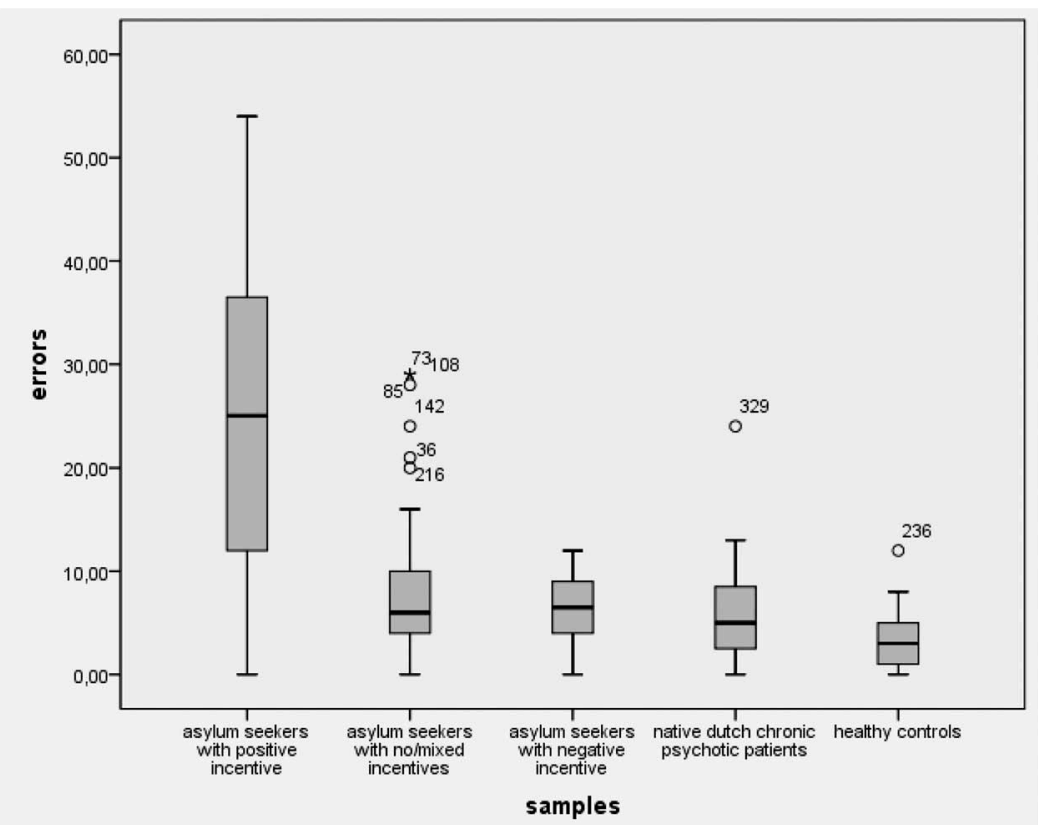

Figure 1. Numbers of errors on the forced-choice task in subsamples. Cut-off $>$ nine errors. 
Our first finding is substantiated by our second: referral center patients with an incentive to deny their impairment, most of whom (79\%) were classified as having a psychotic disorder, made significantly more errors than healthy controls on a PVT, whereas they performed at a similar level as native Dutch, chronic psychotic patients. As a matter of fact, a non-trivial minority - $21 \%$ - of both groups failed on the forced-choice test. As neither of these two patient groups had obvious motives to exaggerate, it is unlikely that their errors reflect lack of effort and/or an attempt to misrepresent their impairments. Psychotic symptomatology was a prominent feature in both groups, which was not the case in the other groups (the other incentive samples of the referral center and healthy controls). Thus, one distinct possibility is that psychotic symptomatology may artificially raise failure rates on forced-choice PVTs of the type used in in the current study.

Third, replicating earlier studies (Van der Heide \& Merckelbach, 2016; Van der Heide, Boskovic, \& Merckelbach, 2017), referral center patients with a positive incentive made significantly more errors on the forced-choice PVT than patients with a mixed or a negative incentive to produce deviant scores. This indicates that our PVT was sensitive to incentives. Yet, combined with the other findings, the conclusion must be that raised error scores do not necessarily point in the direction of intentional symptom distortion motivated by positive incentives because psychotic patients without incentives may also exhibit raised error scores.

It may well be the case that impairments that are central to psychosis, notably disturbances in semantic memory, visual memory, verbal learning, and attention (e.g. Saykin et al., 1991), interfere with the cognitive efficiency required to conduct even a relatively easy task such as a forced-choice PVT. Also, negative symptoms such as apathy and avolition may contribute to suboptimal performance on a PVT (Gorissen, Sanz, \& Schmand, 2005). Another possibility is that medication, at least conventional antipsychotic drugs, may exacerbate cognitive impairments to such degree that these impairments suppress performance on simple cognitive tasks (e.g. Kasper \& Resinger, 2003). The extent to which both factors, disturbances inherent to psychosis and side-effects of medication, are prominently present in samples of psychiatric patients may explain why some researchers reported relatively low rates of PVT failures in psychotic patients (Schroeder \& Marshall, 2011), whereas others found considerable proportions failing PVTs (e.g. Van der Heide \& Merckelbach, 2016; Van der Heide, Boskovic, \& Merckelbach, 2017).

A strength of our study is that almost all referral center patients consented to participate, which makes it unlikely that hidden selection effects distorted our results. However, a number of limitations of the present study are important to discuss. First, a limitation is that social workers only checked the files for the presence or absence of documented incentives (e.g. being involved in a custody dispute). We did not look into the presence or absence of other types of 
incentives, the types that are more difficult to objectify and that are usually not mentioned in medical files, such as previous experiences of care being denied. Second, the referral center patients were the only group for whom external incentives were taken into consideration. We assumed that the other groups would have no such incentives, but we cannot rule out their presence. For example, one Dutch patient with a particularly high error score informed the nurses that he was anxious that a low error score might result in relocation to another facility with less care. Third, the fact that mean error scores and failure rates of the negative incentive group and those of Dutch chronic psychotic patients were highly similar does not imply that the error scores of referral center patients were unaffected by cultural factors (e.g. different test taking attitudes; Ardila, 2005). Clearly, the presence of one confounder does not necessarily rule out the presence of another. Finally, in our study we relied on diagnostic classification and did not collect specific symptom severity data. Determining at which levels of symptom severity performance on symptom credibility tests becomes compromised has considerable practical value for clinicians who want to know whether it is safe to administer PVTs or any other tests to evaluate the credibility of symptoms for that matter. Future studies could systematically relate PVT scores to measures of psychotic symptom severity, such as the Positive and Negative Symptoms Scale (PANSS; Kay, Fiszbein, \& Opler, 1987), to cognitive aberrations typical for psychosis (e.g. lack of attentional control), and to antipsychotic drug use, preferably in patients motivated to perform optimally.

\section{Conclusions}

In sum then, refugees with no obvious incentive to exaggerate their impairments may still fail a simple forced-choice PVT. Our study offers preliminary evidence that, apart from cultural and linguistic differences, current psychotic symptoms may be a confounder when PVT tests are administered to this group. The implication of this is straightforward: clinicians should be cautious in administering PVTs to refugees with psychotic symptoms and the presence of such symptoms may be a reason to set cutoffs at more stringent levels and to use multiple PVTs (Schroeder \& Marshall, 2011).

\section{Note}

1. Error scores exceeding chance level ( $>36$ ) only emerged in the subsample of referral center patients with a positive incentive. In this subsample, 38 patients ( $16 \%$ of all referral center patients) had such a score. 


\section{Acknowledgments}

The authors would like to thank Hanneke Bot, former head of the clinical facility where this study took place, for her review of the concept version of this article.

\section{Disclosure statement}

No potential conflict of interest was reported by the authors.

\section{References}

American Psychiatric Association. (2000). Diagnostic and statistical manual of mental disorders (4th ed. text rev.). Washington, DC: Author.

Ardila, A. (2005). Cultural values underlying psychometric cognitive testing. Neuropsychology Review, 15, 185-195.

Bush, S. S., Ruff, R. M., Tröster, A. I., Barth, J. T., Koffler, S. P., Pliskin, N. H., ... Silver, C. H. (2005). Symptom validity assessment: Practice issues and medical necessity. Archives of Clinical Neuropsychology, 20, 419-426.

Dandachi-FitzGerald, B., Merckelbach, H., \& Ponds, R. W. (2017). Neuropsychologists' ability to predict distorted symptom presentation. Journal of Clinical and Experimental Neuropsychology, 39, 257-264.

Dandachi-FitzGerald, B., Ponds, R. W. H. M., Peters, M. J. V., \& Merckelbach, H. (2011). Cognitive underperformance and symptom over-reporting in a mixed psychiatric sample. The Clinical Neuropsychologist, 25, 812-828.

Davis, J. J. (2018). Performance validity in older adults: Observed versus predicted false positive rates in relation to number of tests administered. Journal of Clinical and Experimental Neuropsychology, 40, 1013-1021.

Edwards, J., Jackson, H. J., \& Pattison, P. E. (2002). Emotion recognition via facial expression and affective prosody in schizophrenia: A methodological review. Clinical Psychology Review, 22, 789-832.

Erdodi, L. A., Nussbaum, S., Sagar, S., Abeare, C. A., \& Schwartz, E. S. (2017). Limited English proficiency increases failure rates on performance validity tests with high verbal mediation. Psychological Injury and Law, 10, 96-103.

Geraerts, E., Kozaric-Kovacic, D., Merckelbach, H., Peraica, T., Jelicic, M., \& Candel, I. (2009). Detecting deception of war-related post-traumatic stress disorder. Journal of Forensic Psychiatry \& Psychology, 20, 278-285.

Glassmire, D. M., Toofanian Ross, P., Kinney, D. I., \& Nitch, S. R. (2016). Derivation and cross-validation of cutoff scores for patients with schizophrenia spectrum disorders on WAIS-IV digit span-based performance validity measures. Assessment, 23, 292-306.

Gorissen, M., Sanz, J. C., \& Schmand, B. (2005). Effort and cognition in schizophrenia patients. Schizophrenia Research, 78, 199-208.

Hunt, S., Root, J. C., \& Bascetta, B. L. (2014). Effort testing in schizophrenia and schizoaffective disorder: Validity indicator profile and test of memory malingering performance characteristics. Archives of Clinical Neuropsychology, 29, 164-172.

Kasper, S., \& Resinger, E. (2003). Cognitive effects and antipsychotic treatment. Psychoneuroendocrinology, 28, 27-38.

Kay, S. R., Fiszbein, A., \& Opler, L. A. (1987). The positive and negative sydrome scale (PANSS) for schizophrenia. Schizophrenia Bulletin, 13, 261-276. 
Lipman, F. D. (1962). Malingering in personal injury cases. Temple Law Quarterly, 35, $141-162$.

Lustig, S. L. (2008). Symptoms of trauma among political asylum applicants: Don't be fooled. Hastings International and Comparative Law Review, 31, 725-739.

Merckelbach, H., Dandachi-FitzGerald, B., van Helvoort, D., Jelicic, M., \& Otgaar, H. (2019). When patients overreport symptoms: More than just malingering. Current Directions in Psychological Science, 28, 321-326.

Merten, T., Thies, E., Schneider, K., \& Stevens, A. (2009). Symptom validity testing in claimants with alleged posttraumatic stress disorder: comparing the morel emotional numbing test, the structured inventory of malingered symptomatology, and the word memory test. Psychological Injury and Law, 2, 284-293.

Montes, O., \& Guyton, M. R. (2014). Performance of hispanic inmates on the Spanish Miller Forensic Assessment Of Symptoms Test (M-FAST). Law and Human Behavior, 38, 428-438.

Morel, K. R. (1998). Development and preliminary validation of a forced-choice test of response bias for posttraumatic stress disorder. Journal of Personality Assessment, 70, 299-314.

Nijdam-Jones, A., \& Rosenfeld, B. (2017). Cross-cultural feigning assessment: A systematic review of feigning instruments used with linguistically, ethnically, and culturally diverse samples. Psychological Assessment, 29, 1321-1336.

Peters, M. J. V., Jelicic, M., Moritz, S., \& Jelinek, L. (2013). Assessing the boundaries of symptom over-reporting using the structured inventory of malingered symptomatology in a clinical schizophrenia sample: Its relation to symptomatology and neurocognitive dysfunctions. Journal of Experimental Psychopathology, 4, 64-77.

Ray, C. L. (2014). Feigning screeners in VA PTSD compensation and pension examinations. Psychological Injury and Law, 7, 370-387.

Saykin, A. J., Gur, R. C., Gur, R. E., Mozley, P. D., Mozley, L. H., Resnick, S. M., ... Stafiniak, P. (1991). Neuropsychological function in schizophrenia: Selective impairment in memory and learning. Archives of General Psychiatry, 48, 618-624.

Schroeder, R. W., \& Marshall, P. S. (2011). Evaluation of the appropriateness of multiple symptom validity indices in psychotic and non-psychotic psychiatric populations. The Clinical Neuropsychologist, 25, 437-453.

Tracy, D. K. (2018). Confessions of a liar-detector: I can tell if you're malingering, but I can't tell why. BJPsych Advances, 24, 316-318.

Van der Heide, D., Boskovic, I., \& Merckelbach, H. (2017). Standard symptom inventories for asylum seekers in a psychiatric hospital: Limited utility due to poor symptom validity. Psychological Injury and Law, 10, 358-367.

Van der Heide, D., \& Merckelbach, H. (2016). Validity of symptom reports of asylum seekers in a psychiatric hospital: A descriptive study. International Journal of Law and Psychiatry, 49, 40-46.

Young, G. (2014). Malingering, feigning, and response bias in psychiatric/psychological injury: Implications for practice and court. Dordrecht: Springer.

Zimmermann, P., Kowalski, J. T., Alliger-Horn, C., Danker-Hopfe, H., Engers, A., Meermann, R., \& Hellweg, R. (2013). Detection of malingering in the assessment of occupational disability in the military. German Journal of Psychiatry, 16, 54-60. 